\title{
Mars: Fretted and Chaotic Terrains ${ }^{1}$
}

\author{
ROBERT P. SHARP \\ Division of Geological and Planetary Sciences \\ California Institute of Technology, Pasadena, California 91109
}

\begin{abstract}
Fretted and chaotic terrains are members of a larger family of lowland terrains on the Martian surface. They have formed in equatorial and midnorthern latitudes, within areas reasonably proximate to the extensive volcanic fields of that region. Both are relatively recent developments. Fretted terrain is characterized by extensive, smooth, lowland plains separated from the old cratered upland by an abrupt escarpment of highly irregular planimetric configuration. Chaotic terrain features jumbled assemblages of large, irregular blocks occupying lowlands or depressions within the old cratered upland. Fretted terrain is thought to evolve by recession of a steep bounding escarpment, leaving a smooth lowland floor at a remarkably uniform level. Escarpment recession is speculatively attributed to undermining by evaporation of ground ice exposed within an escarpment face, or, under a different environment, by groundwater emerging at its foot. The uniform floor level may reflect the original depth of frozen ground. Removal of debris shed by the receding escarpments could be by eolian deflation, subsequent to weathering by unknown processes to produce material of uniformly small grain size, or by fluvial transport under a vastly different climatic environment. Chaotic terrain is attributed primarily to localized collapse of the cratered upland owing to removal of subsurface material, either ground ice or magma. The ground ice hypothesis suffers from possible quantitative inadequacies, but evacuation of magma seems feasible because of the extensive volcanism in the northern hemisphere. Following collapse, ground ice sapping could have been effective in causing slumps and in modifying the collapsed blocks. Eventually the floors of some areas of chaotic terrain may have been smoothed to the condition of fretted terrain, as suggested by their intimate association. These terrains reflect significant activity on the Martian surface and within the Martian interior during relatively recent times. If liquid water has been the prime agent involved in developing fretted terrain, then it is a fossil feature and carries an implication of an enduring Martian environment vastly different from the environment at present.
\end{abstract}

Fretted terrain is but one of a variety of lowland terrains on the Martian surface that, like members of an isomorphous series, have some characteristics in common and are shaped by some of the same genetic processes. These terrains are artificially separated to facilitate handling (Table 1). At one extremity are the south polar pits described elsewhere [Sharp, 1973]; at the other are the huge equatorial troughs.

Fretted terrain is characterized by smooth, flat, lowland areas separated from a cratered upland by abrupt escarpments of complex planimetric configuration and a maximum estimated height approaching 1-2 km (Figure 1). It is the product of some unusual erosive or

1 Contribution 2264, Division of Geological and Planetary Sciences, California Institute of Technology, Pasadena, California.

Copyright (๑) 1973 by the American Geophysical Union. abstractive process that has created steep escarpments and caused them to recede into a complex planimetric configuration leaving behind a smooth, flat lowland surface. Although a relatively late development on the Martian surface, fretted terrain has formed over a significant span of time, and in places it may be older than some phases of the extensive northern hemisphere volcanism [Carr, 1973].

Chaotic terrain differs from fretted terrain, with which it is geographically associated, in having a rough floor topography featuring a haphazard jumble of large angular blocks, and by arc-shaped slump blocks on its bounding escarpments, often with arc-shaped fractures extending into the adjoining upland (Figure 2). Chaotic terrain was initially recognized and described from features incompletely shown on Mariner 6 frames [Sharp et al., 1971]. Its existence has now been confirmed by Mariner 9 pictures, and the characteristics, location, and areal extent of 
TABLE 1. Some Types of Martian Lowland Terrains

\begin{tabular}{|c|c|c|}
\hline Terrain Type & Description & Type Area \\
\hline Pitted terrain & $\begin{array}{l}\text { Abundant, flat, smooth-floored, steep-walled pits, } \\
\text { tens of kilometers across, an estimated } 100 \text { to } 400 \\
\text { meters deep, developed in sedimentary blankets. }\end{array}$ & $\begin{array}{l}\text { South polar } \\
\text { region }\end{array}$ \\
\hline Etched terrain & $\begin{array}{l}\text { Exhumed, rough-floored, lowland areas of highly } \\
\text { irregular planimetric outline produced by integra- } \\
\text { tion of pits developed in sedimentary blankets. }\end{array}$ & $\begin{array}{l}\text { South polar } \\
\text { region at } \\
60^{\circ} \text { to } 65^{\circ} \mathrm{S}\end{array}$ \\
\hline Fretted terrain & $\begin{array}{l}\text { Smooth-floored lowland bounded by abrupt escarp- } \\
\text { ments of uniform height and highly irregular plani- } \\
\text { metric configuration; tributary flat-floored chasms, } \\
\text { developed into an old cratered surface } 1 \text { to } 2 \mathrm{~km} \\
\text { higher. }\end{array}$ & $\begin{array}{l}40^{\circ} \mathrm{N} \\
\text { between } 280^{\circ} \\
\text { and } 350^{\circ}\end{array}$ \\
\hline Hollowed terrain & $\begin{array}{l}\text { A complex of elongate U-shaped hollows, an esti- } \\
\text { mated } 2 \text { to } 3 \mathrm{~km} \text { deep, strongly controlled by in- } \\
\text { teresting sets of linear fractures. }\end{array}$ & $\begin{array}{l}5^{\circ} \text { to } 10^{\circ} \mathrm{S} \\
\text { between } \\
90^{\circ} \text { and } 110^{\circ}\end{array}$ \\
\hline Chaotic terrain & $\begin{array}{l}\text { Jumbled chaos of slump and collapse blocks in low- } \\
\text { land depressions bounded by steep walls with arcuate } \\
\text { fractures. }\end{array}$ & $\begin{array}{l}0^{\circ} \text { to } 10^{\circ} \mathrm{S} \\
\text { between } \\
15^{\circ} \text { and } 35^{\circ}\end{array}$ \\
\hline Troughed terrain & $\begin{array}{l}\text { Huge, steep-walled troughs, up to several hundred } \\
\text { kilometers long and possibly } 5 \mathrm{~km} \text { deep, integrated } \\
\text { into a belt } 2700 \mathrm{~km} \text { long by } 500 \mathrm{~km} \text { wide, wall side } \\
\text { slumps, intratrough ridges, orthogonal and dendritic } \\
\text { wall scers. }\end{array}$ & $\begin{array}{l}0^{\circ} \text { to } 15^{\circ} \mathrm{S} \\
\text { between } \\
50^{\circ} \text { and } 90^{\circ}\end{array}$ \\
\hline
\end{tabular}

chaotic terrain have been more accurately and completely defined.

Like fretted terrain, chaotic terrain occupies lowland settings within an older, cratered upland surface. It has clearly developed at the expense of this cratered upland, and its relatively youthful age is further demonstrated by a paucity of recognizable craters.

This is a preliminary report on the nature and possible genesis of these two terrain types. More will undoubtedly be written about them as the Mariner 9 pictures and data are more thoroughly analyzed.

\section{Geographic Relationships}

Fretted terrain is recognized principally in five separate areas within the northern hemisphere, with only a minor extension south of the equator. Other areas of fretted terrain may exist, but they are obscured or modified beyond certain recognition. The largest area and most typical development is along and for $5^{\circ}$ and $10^{\circ}$ on either side of $40^{\circ} \mathrm{N}$ latitude between longitudes $280^{\circ}$ and $350^{\circ}$. This region of fretted terrain debouches northward into an extensive lowland plain which occultation measurements show to be one of the topographically lowest parts of the northern hemisphere [Kliore et al., 1973]. The fretted terrain so far recognized covers a total of about $4.75 \times 10^{6} \mathrm{~km}^{2}$, or $3 \%$ of the Martian surface.

Chaotic terrain is geographically associated on the west with the huge equatorial troughs and on the east and north with fretted terrain. It is, perhaps, genetically related to both, but in setting and characteristics it is more closely allied to fretted terrain into which it grades in many places (Figure 3). Chaotic terrain is concentrated principally into an equatorial region from about $3^{\circ} \mathrm{N}$ to $12^{\circ} \mathrm{S}$ between longitudes $15^{\circ}$ and $40^{\circ}$, where it is the dominant feature. Small patches of chaotic terrain are more widely scattered, ranging as far west as $75^{\circ}$ longitude and north to $15^{\circ}$ latitude. Some of these are associated with areas of fretted terrain, but others are isolated and look as though they might have developed on the sites of relatively large craters. The total area of chaotic terrain is about $5.5 \times 10^{5} \mathrm{~km}^{2}$. This is about one-third the area estimated in 1969 from Mariner 6 pictures. It is now clear that areas of indistinctly recorded troughed and fretted terrains were included in the 1969 value. Chaotic 
terrain makes up only about $0.4 \%$ of the total Martian surface.

\section{Description of Fretted Terrain}

Planimetric configuration. A striking characteristic of fretted terrain is its irregular planimetric pattern (Figures 1 and 4). The steep escarpment separating lowlands from uplands typically traces a ragged course with deep embayments, projecting headlands, and smaller arc-shaped indentations. Only where strongly controlled by older structures, such as linear fractures or crater scars, are the escarpments broadly linear and curvilinear. Even there, association with other forms yields a complex pattern.

Especially noteworthy are the steep-walled, flat-floored chasms or channels, some linear and some irregularly winding (Figure 1), that deeply penetrate the surrounding upland and debouch in tributary fashion into areas of smooth lowland. The larger and principal channels increase in width northward but terminate at the edge of the fretted terrain region where it borders on the area of lowland plain to the north. Also characteristic are numerous islandlike outliers, resembling the mesas, buttes, and towers of Monument Valley, rising above the smooth-floored lowland (Figure 5). These outliers become generally smaller, more widely spaced, and less numerous outward from the bounding escarpment.

Floor characteristics. The lowland floors of fretted terrain appear smooth at a wide-angle resolution of $1 \mathrm{~km}$. Narrow-angle pictures (Figure 5), with resolutions of 200-300 meters, confirm this general smoothness, although they

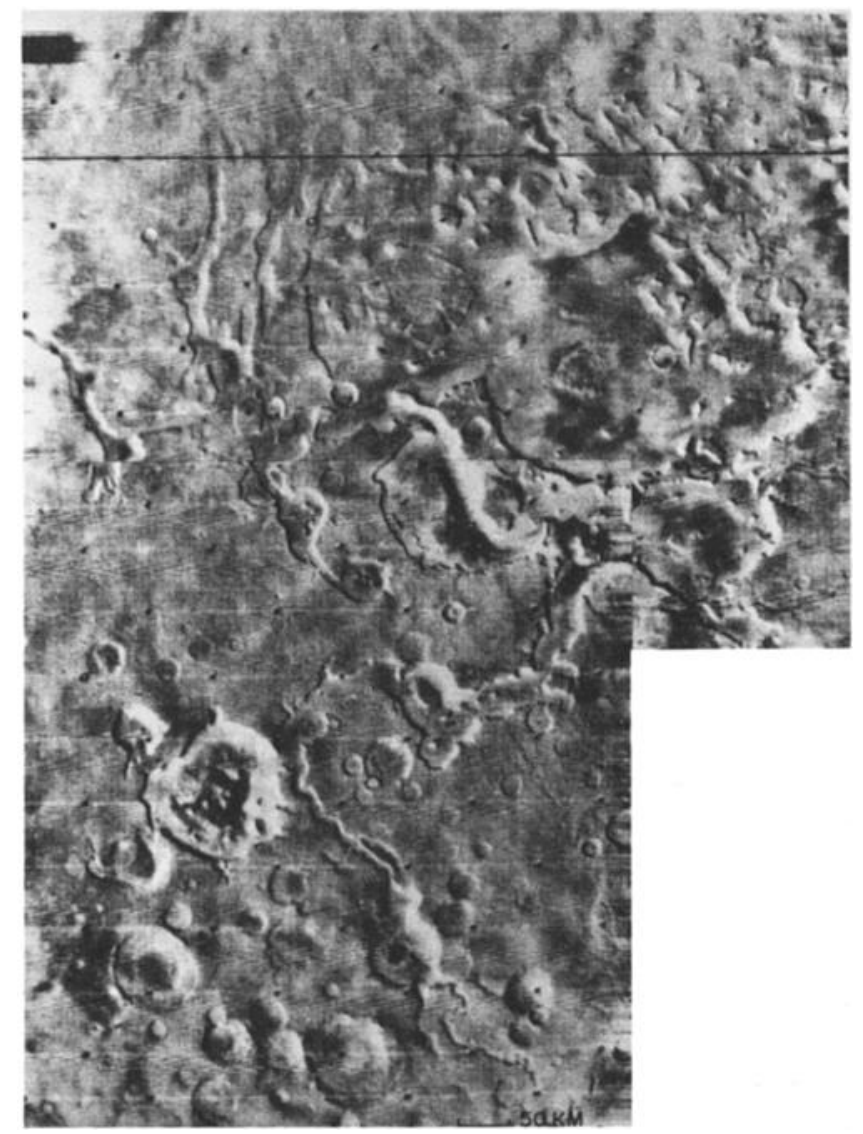

Fig. 1. Area of fretted terrain centered at $40.1^{\circ} \mathrm{N}$ latitude, $337.4^{\circ} \mathrm{W}$ longitude, displaying typical complex planimetric patterns, smooth floor, abrupt escarpments, separated outliers, and sinuous flat-floored tributary chasms (MTVS 4251-47, DAS 09378154; MTVS 4251-56, DAS 09378294 ). 


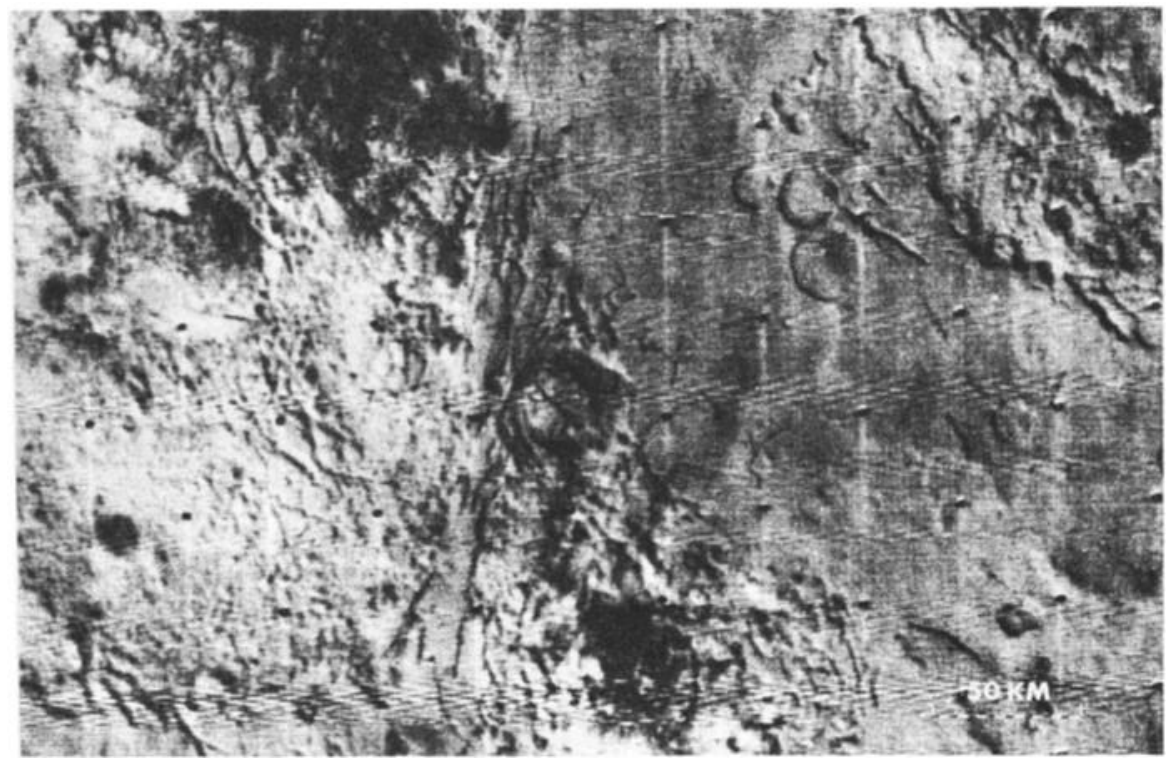

Fig. 2. Representative area of chaotic terrain at $6.5^{\circ} \mathrm{S}, 26.3^{\circ} \mathrm{W}$, with crescent-shaped blocks and arcuate fractures strongly suggestive of collapse (MTVS 4247-44, DAS 09232974).

show some low undulations and a few local areas of rough topography that may represent complex structures within the Martian crust, possibly the residual roots of old deeply penetrating craters. Most floors display only an occasional small, fresh, bowl-shaped crater, but a few scattered craters up to $25 \mathrm{~km}$ in diameter are seen. Irregular mottling by albedo markings is somewhat more prominent than on adjacent uplands, and some of these markings mimic the configuration of a nearby escarpment.

Extensive reaches of the lowland floor appear to lie at an impressively uniform altitude, as though reduced to a common base level. This holds true even for the long penetrating fingers of tributary chasms and for the floors of larger craters integrated into the lowland. The uniform height of long reaches of the bounding escarpment is another manifestation of this relationship.

Wall characteristics. Escarpments enclosing the lowlands usually break off from the uplands with a sharp, well-defined brink. Escarpment slopes appear to be mostly straight and smooth without marked concavity. Orthogonal or dendritic scarring is largely absent, and slump blocks, so characteristic of chaotic terrain, are lacking. No layering or structure is identifiable in the wall materials; they appear homogeneous and massive.

Escarpment height is largely a matter of estimation. If a conservative $10^{\circ}$ slope is assumed, heights of 0.5 to $1 \mathrm{~km}$ are common. Some escarpments are lower; few, if any, appear to exceed 2 $\mathrm{km}$. Ultraviolet spectrometer profiles confirm heights of this general magnitude.

Upland surface. The upland surface enclosing areas of fretted terrain is mostly well cratered, but otherwise it is relatively smooth. Upland craters are locally embayed by the escarpments of fretted terrain, and in such instances the crater floors are integrated into the lowlands.

\section{Description of Chaotic Terrain}

Floor characteristics. The most distinctive feature of chaotic terrain is its rough floor topography, most typically an irregular jumble of angular blocks of various sizes, many preserving remnants of the relatively smooth upland surface (Figure $6 a$ ). The largest blocks are several kilometers across and tens of kilometers long. At some sites, the angular shape and equant dimensions of blocks may reflect control by two or more sets of linear fractures. Once formed, these blocks seem to suffer further breakup and reduction in size, and the equant blocks ultimately become pyramidal. Eventually, they may be entirely destroyed, leaving a smooth floor like that of fretted terrain.

Bounding escarpments. Some areas of chaotic 
terrain involve a transition from slightly fractured upland through a highly fractured zone to a jumble of irregular blocks (Figure 2). Other areas are sharply bounded by an abrupt escarpment of irregular planimetric configuration (Figure 3). The vertical relief of this escarpment is a matter of estimation, but most escarpments seem to range from something less than $1 \mathrm{~km}$ to a little more than $2 \mathrm{~km}$, with a maximum approaching 3 $\mathrm{km}$. They are, in places, higher than the escarpments bounding most areas of fretted terrain. Locally, chaotic terrain escarpments display a succession of crescent-shaped indentations, and on their faces are crescent-shaped slump blocks up to several kilometers wide and tens of kilometers long. Some of these blocks bear remnants of the upland surface, now rotated backward into the escarpment face. Locally, arcuate markings, presumably fractures, extend back into the surrounding upland with similar scale and configuration. Most escarpments have a sharp, well-defined brink, and a few of the highest display orthogonal scarring like that seen on the walls of the large equatorial troughs.

\section{Age Relationships}

Fretted terrain appears to be among the younger landform developments of the Martian surface, but not all areas of fretted terrain are of a single age. Fretted terrain has clearly developed at the expense of the old cratered surface of Mars, which constitutes the adjacent upland. The smooth floor of most areas of fretted terrain is only weakly cratered, primarily by small, fresh, bowl-shaped craters. This suggests relative youth, although accumulation and erosion on such floors may obscure some craters, making the floors look younger than they really are.

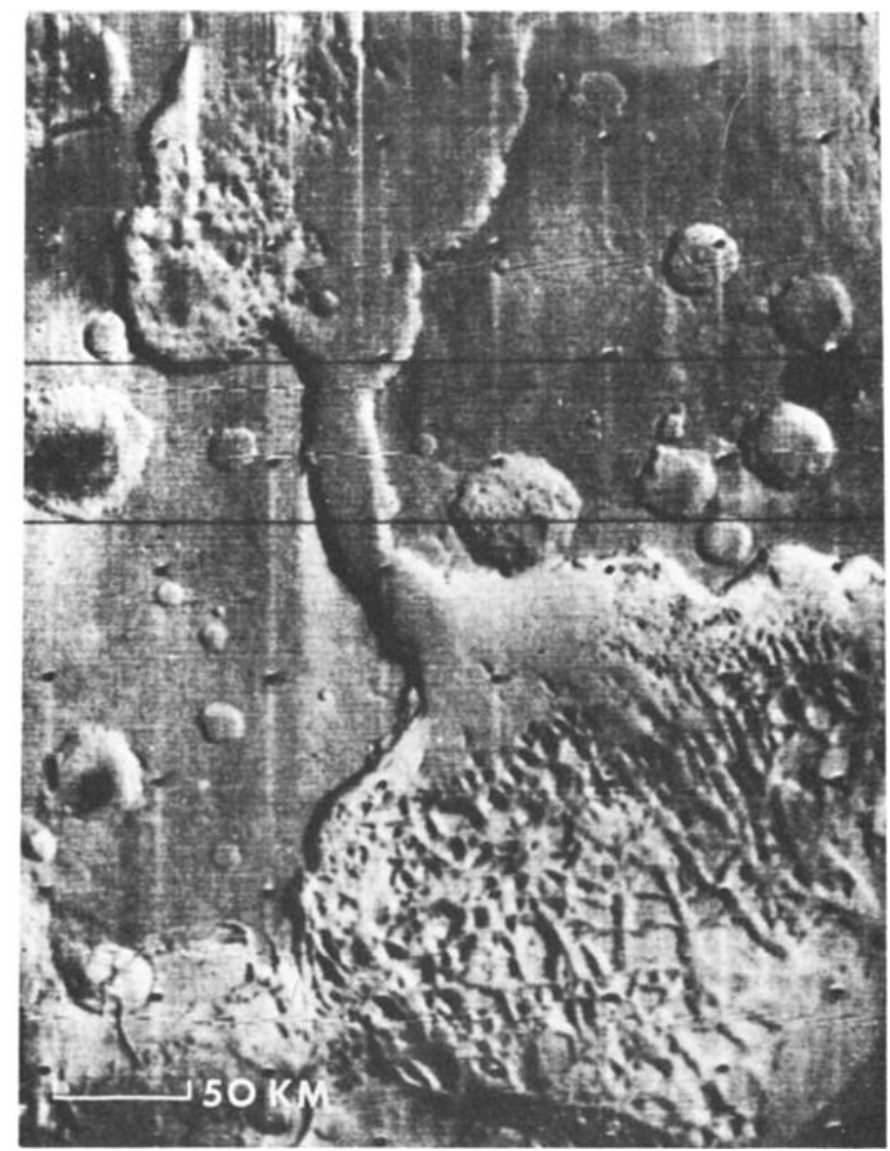

Fig. 3. Chaotic terrain associated with smooth-floored areas of fretted terrain; crescent-shaped slump blocks at left margin of lower area (MTVS 4201-60, DAS 07686808). 


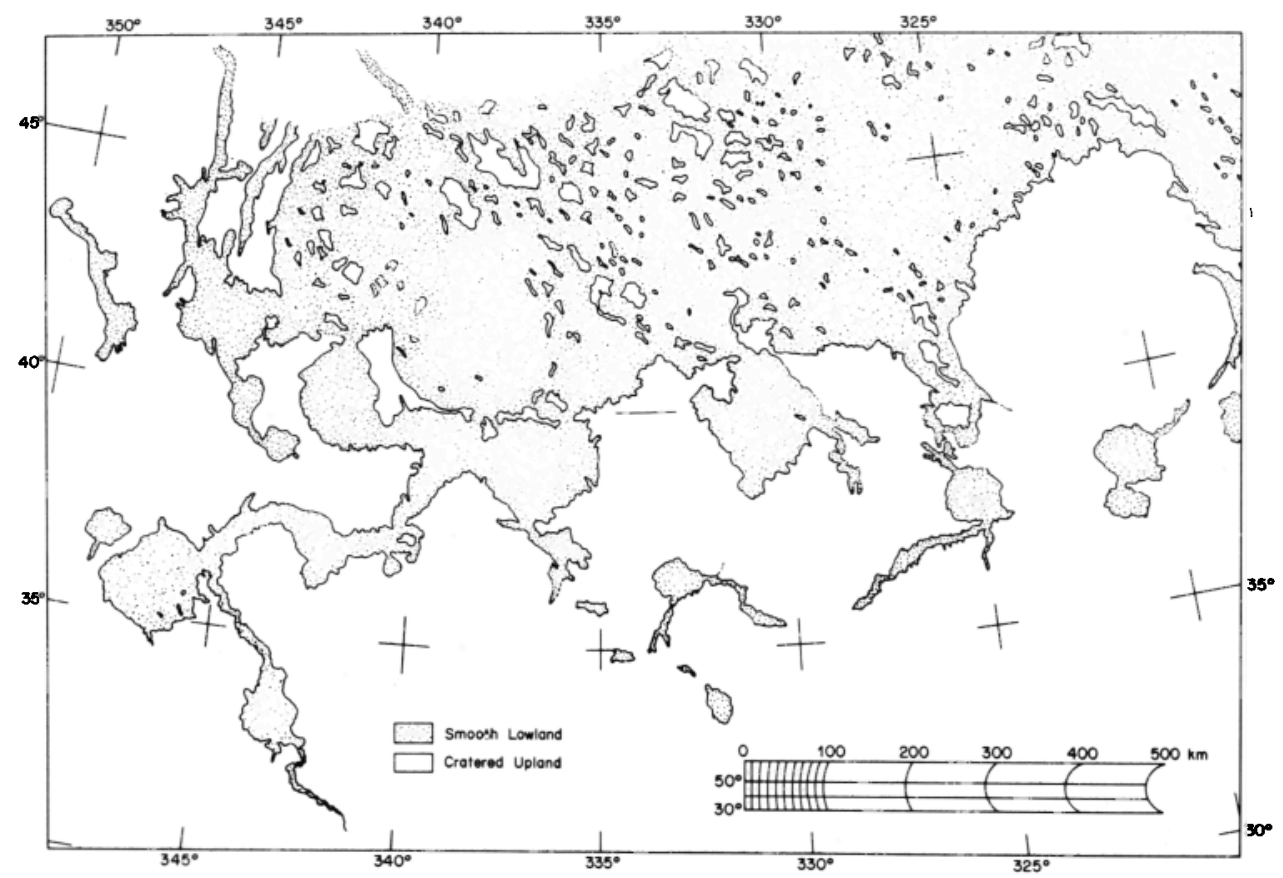

Fig. 4. Map illustrating complex planimetric configurations of fretted terrain with abundant outliers in northern mid-latitudes, sketched from uncontrolled mosaic of Mariner 9 pictures.

At least some fretted terrain must have a modest antiquity for it appears to be partly buried along the western edge of an extensive volcanic field between latitudes $5^{\circ}$ and $15^{\circ}$ north near longitude $75^{\circ}$. The date of volcanism is not rigorously known, but crater frequencies and other considerations suggest an age of the order of hundreds of millions of years [Hartmann, 1973; Carr, 1973].

At least one area of fretted terrain has subdued outlines suggestive of mantling by a blanket of younger material (Figure 7). This impression of greater age is substantiated by a much larger than normal crater population. Other areas of irregular topography elsewhere on Mars have characteristics suggesting that they may represent fretted terrain, now so modified as to be virtually unrecognizable. Thus, the fretting process may have embraced a considerable span of time, and not all the recognizable areas of fretted terrain have the same age.

Chaotic terrain is also judged to be youthful on essentially the same bases. However, the seeming paucity of craters, even of the small bowl-shaped variety, within areas of chaotic terrain may be due in part to the difficulty of recognizing such features within the chaos of jumbled blocks. Furthermore, craters could be rather quickly obscured on the steep sides of the blocks. Associated areas of fretted and chaotic terrain, of which there are a number, cannot be too different in age, and the generally sharp outlines of their features strongly suggest relative youth.

\section{Genesis of Fretted and Chaotic Terrains}

The following statements on genesis are necessarily highly speculative. The development of fretted terrain is thought to be initiated by some structural or topographic break in the old cratered Martian surface. The wall of a large crater, a linear crack, or a winding channel may have, in different instances, served as the initiating locus.

Once a steep escarpment is created, in areas favorable to the formation of fretted terrain, it recedes by an undermining or sapping mechanism, maintaining its steepness but developing a complex planimetric configuration. This is the fretting process. Scarp recession leaves a smooth, flat floor and isolates outlying islandlike buttes, mesas, and towers. The bounding slopes of these 
outliers also recede, reducing them in size and eventually in number.

On earth, scarp recession occurs most readily where there is some structural or stratigraphic inhomogeneity near the scarp base to facilitate undermining. Horizontal strata with a massive member overlying weak incompetent layers, as occurs in the plateau region of the southwestern United States, provide nearly ideal conditions. The undermining on earth is produced largely by differential weathering and groundwater sapping.

Layering within the materials of the upper 1-2 $\mathrm{km}$ of the Martian crust is not out of the question, and it might involve a volcanic sequence or a thick deposit of eolian detritus. However, such materials would have to be relatively old, as the surface they underlie is scarred by many large craters. An attractive alternative is the possibility that otherwise relatively homogeneous nearsurface Martian material has a sharp, planar, physical discontinuity at a depth of 1 to $2 \mathrm{~km}$. Such a discontinuity might have formed in relation to frozen ground developed to that depth.

An evaluation of the possibilities of perennially frozen ground (permafrost) and ground ice under the surface of Mars is thus in order. Direct observations of Martian surface temperatures, both earth-based and from spacecraft, indicate that a model formulated by Leighton and Murray [1966] permits calculations of seemingly reasonable mean annual surface temperatures for various latitudes. From this it appears that the surface thermal regimen of Mars is favorable to the development of frozen ground everywhere,
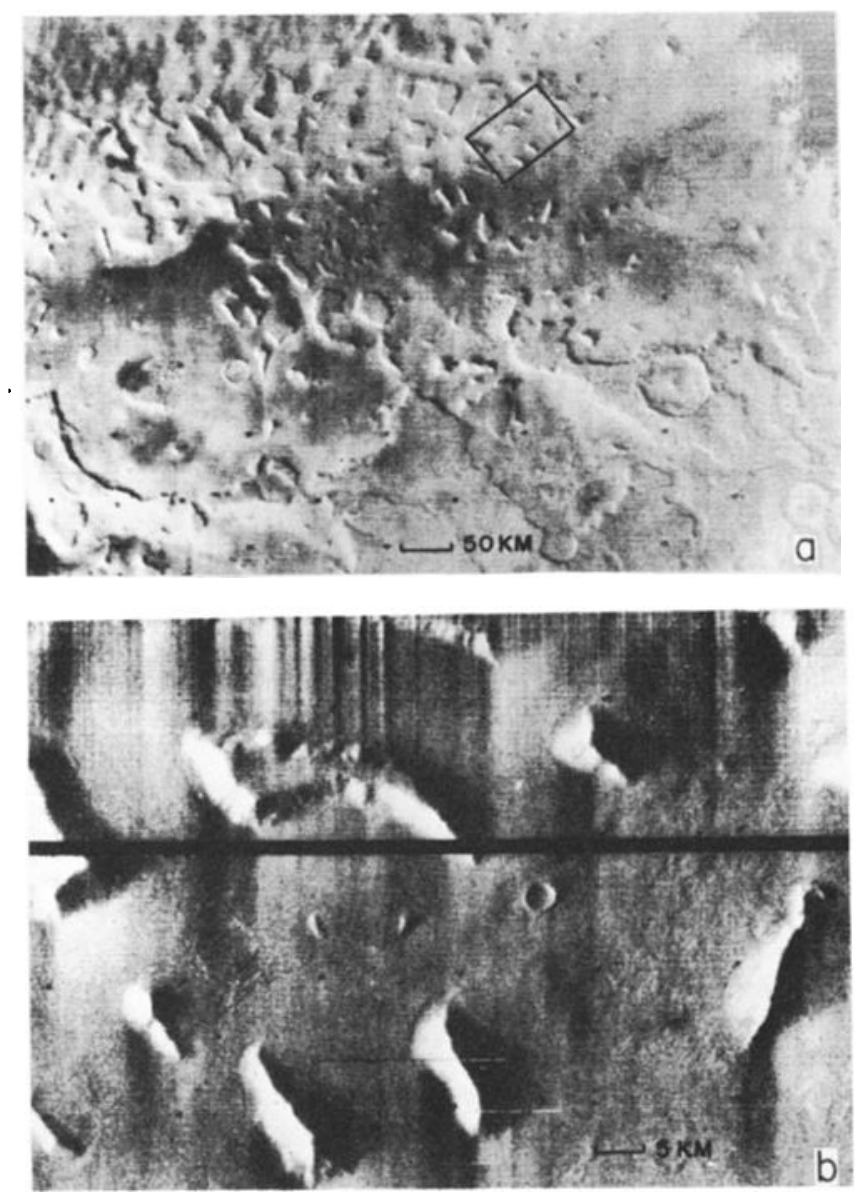

Fig. 5. Wide- and narrow-angle pictures of fretted terrain to illustrate angularity of outlines, smoothness of floor, abruptness of escarpments, and nature of outliers (MTVS 4212-69, DAS 08047308; MTVS 4212-72, DAS 08047343). 

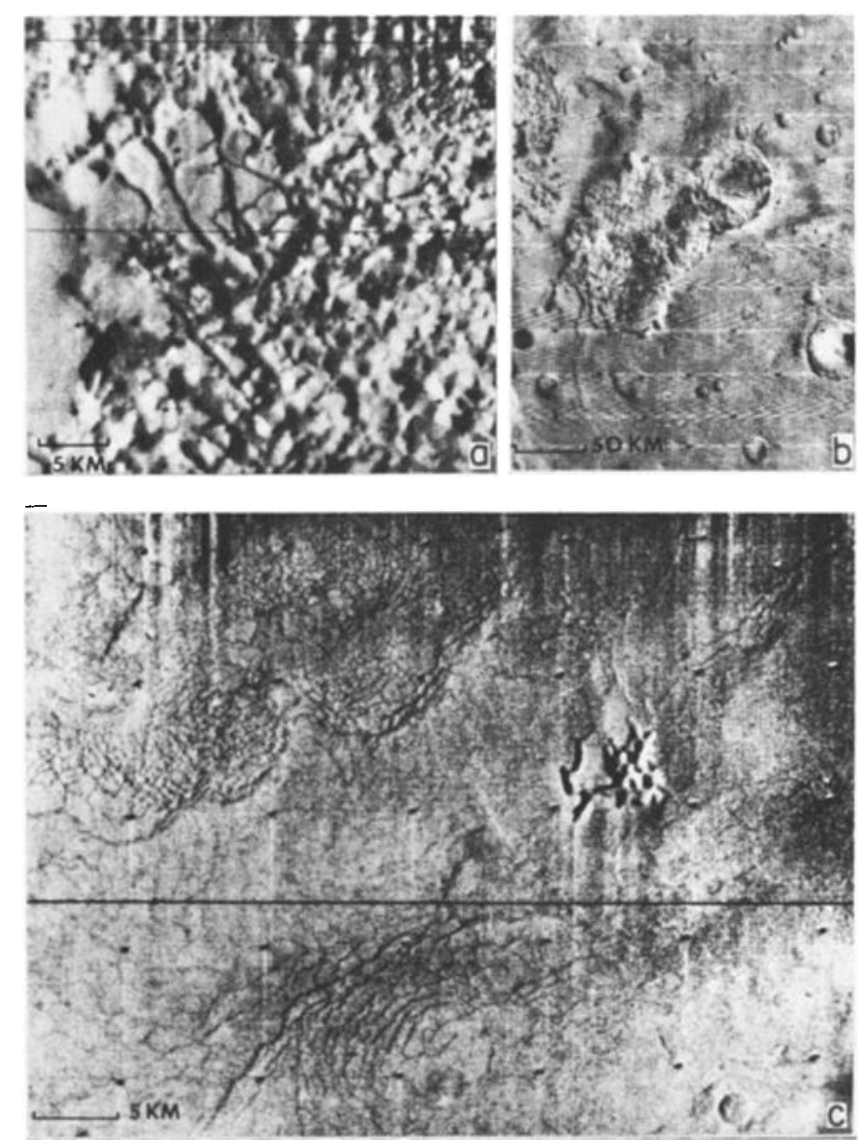

Fig. 6. A composite of one wide-angle and two narrow-angle pictures of chaotic terrain showing (a) details of angular blocks (MTVS 4201-30, DAS 07686213); (b) small isolated area of chaotic terrain (MTVS 4247-40, DAS 09232904); and (c) arcuate fracturing suggestive of collapse leading to development of chaotic terrain at $1.9^{\circ} \mathrm{S}, 186.5^{\circ} \mathrm{W}$ (MTVS 4209-75, DAS 07938353).

including the equatorial region where the mean annual temperature is in the neighborhood of $-60^{\circ} \mathrm{C}$. The important questions are: How thick might the frozen layer be? Could it contain significant quantities of ground ice, particularly in a segregated state?

Nothing is known for certain about the internal geothermal flux of Mars, and the insulating properties of its surface materials are a subject of estimation. However, a working assumption that the Martian geothermal flux is perhaps onehalf that of earth and that insulation factors such as vegetation and snow cover on earth are two or three times as effective as the presumably fragmented debris on the barren Martian surface, along with the much lower Martian surface temperatures, suggest that frozen ground could extend to depths 2-4 times greater on Mars than on earth.

On earth the most representative maximum depths of frozen ground are 600-650 meters [Price, 1972], although an anomalous 1500 meters has been reported. Mean annual surface temperatures at these sites are currently $-10^{\circ}$ to $-15^{\circ} \mathrm{C}$. However, this deep frozen ground may be a product of Pleistocene chilling when surface temperatures were probably distinctly lower. These figures suggest that the ground beneath the Martian surface could be frozen to depths conservatively estimated at $1-3 \mathrm{~km}$.

More important than depth of freezing is whether the postulated Martian frozen ground contains any significant quantity of frozen volatiles. Only in the extreme polar regions are 
temperatures low enough to permit formation of solid $\mathrm{CO}_{2}$. Elsewhere the most likely frozen volatile is water. On earth the ice in frozen ground represents water of meteoric origin. The amount of water vapor currently in the Martian atmosphere is too small to form more than a small amount of ice dispersed through a few tens of meters of ground, and that would be poleward of $40^{\circ}-50^{\circ}$ latitude [Leighton and Murray, 1966]. If significant masses of $\mathrm{H}_{2} \mathrm{O}$ ground ice derived from meteoric sources exist under the Martian surface, they must be fossil, reflecting major secular or periodic climatic variations in the past.

An interesting alternative is that ground ice on Mars represents water substance that never reached the surface but was captured by freezing within the crust owing to the extremely low temperature conditions. This is a speculation worth entertaining, and it could help account for the relative abundance of $\mathrm{CO}_{2}$ and paucity of
$\mathrm{H}_{2} \mathrm{O}$ in the present Martian atmosphere, although other explanations for the $\mathrm{CO}_{2} / \mathrm{H}_{2} \mathrm{O}$ relationship have been proposed [McElroy, 1972]. The degassing associated with the recent northern hemisphere volcanism may have contributed significantly to Martian ground ice, particularly in areas surrounding the volcanic field. Ground ice of this origin would represent a rather recent development within Martian history, since this volcanism is relatively young [Carr, 1973; Hartmann, 1973].

On earth ground ice exists within the interstices of frozen crustal materials and as segregated bodies in the form of layers, lenses, and dikes. It is the deterioration of these segregated bodies that causes differential sinking and collapse of the land surface. We have no way of knowing whether ground ice on Mars would occur in segregated bodies or not, but the speculation that it does is permissible.

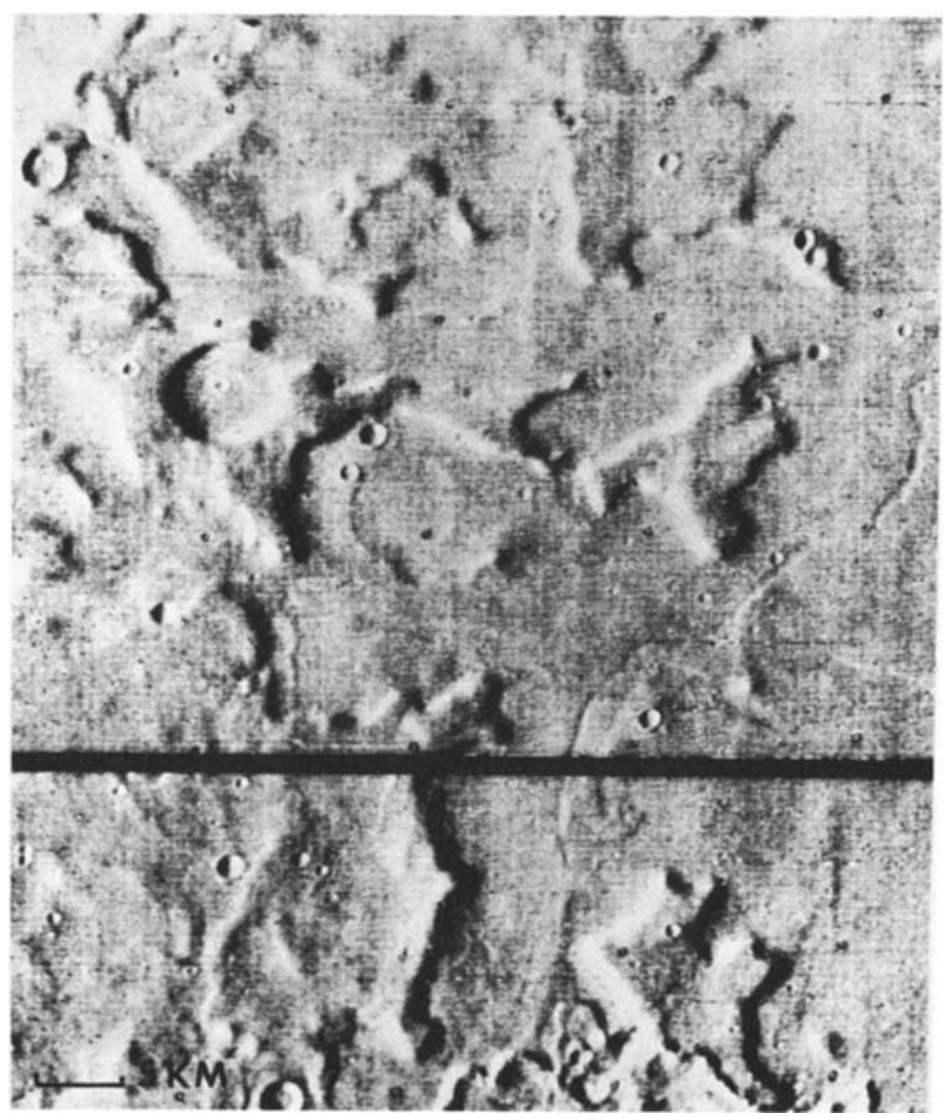

Fig. 7. An area of older blanketed and more abundantly cratered fretted terrain at $44^{\circ} \mathrm{N}, 61.5^{\circ} \mathrm{W}$ (MTVS 4233-92, DAS 08731179). 
The possibility that the surface beneath Mars in areas of fretted terrain has been frozen to a depth of about 1-2 km thus seems reasonable. This could be the discontinuity, or the base level, that is expressed in the remarkable uniformity of cliff height and the concordance of the smooth floors of fretted terrain, a concept developed in greater detail by L. A. Soderblom and D. B. Wenner (unpublished data, 1973).

On earth, a common cause of cliff recession is undermining by groundwater. On Mars, a comparable function may currently be performed by ground ice. Undermining could occur when ground ice, either in segregated bodies or in rock interstices, is exposed on the scarp face and melts or evaporates, the latter being more likely under present climatic conditions. This could allow the rock materials to crumble, undermining the escarpments and causing recession while maintaining steepness. Inhomogeneities in the amount and distribution of ground ice and in the nature and structure of materials could result in differential recession producing the highly irregular escarpment seen on Mariner 9 pictures.

The recessional process would soon come to a halt, if the debris shed by the escarpment were not removed. Under current conditions, wind is generally regarded as a likely agent of debris removal. For wind to be effective in any significant degree, all the rock detritus must be relatively fine grained. If that is not the initial condition of the detritus shed from the escarpments, then it must be reduced to that state by weathering. On Mars this is not an easy task; thermal fracturing seems an inadequate mechanism [Ryan, 1962] for particle reduction, but perhaps it should not be wholly ignored; M. C. Malin (work in preparation) is evaluating the matter of salt weathering.

The alternative possibility that the undermining is effected by groundwater, as urged by Milton [1973], has the virtue that the water, if plentiful enough, could carry the resulting debris northward into the lower area of relatively featureless plain lying north of fretted terrain. The problem involved in postulating groundwater action and fluvial transport is the requirement of a wholly different climatic and atmospheric environment on Mars that would permit the existence of liquid water on the Martian surface. Such conditions would have had to exist for a considerable time; judging by the amount of debris that was removed to create the extensive area of fretted terrain and the probability that the process worked slowly, it was not a catastrophic procedure. If it is of fluvial origin, fretted terrain is fossil, and the implication of major and enduring climatic change is highly significant.

Why fretted terrain is not more widely developed on the Martian surface is a moot question. It may be that proximity to the large-scale volcanism of the northern hemisphere has been a factor in terms of larger than normal quantities of degassed volatiles to form ground ice or groundwater and in deformation of the surface to initiate receding scarps. The low-lying plain area farther north may also be a consideration.

Another hypothesis, perhaps worthy of consideration, is that frozen ground and significant quantities of ground ice developed under these now fretted parts of the Martian surface to a depth of $10 \mathrm{~km}$ rather than 1 or $2 \mathrm{~km}$. If $10 \%$ of this frozen mass were in the form of segregated ice bodies that distended the ground, then a $10 \%$ decrease in volume would occur if the ice were removed by melting or evaporation. This would produce about $1 \mathrm{~km}$ of sinking of the ground level. However, $10 \mathrm{~km}$ seems an extreme thickness for frozen ground, and fretted terrain does not look at all like surfaces on earth that have collapsed because of ground ice thawing.

That subsidence, fracturing, and slumping have played a part in the development of chaotic terrain was inferred from the Mariner 6 pictures of 1969 and now seems established by Mariner 9 . Subsidence, of a type possibly leading to the formation of chaotic terrain, is strongly suggested by the fracture pattern evident in a narrow-angle picture (Figure $6 c$ ). Since subsidence and slumping are usually initiated by removal of subsurface material, the crux of the origin of chaotic terrain becomes, What process or processes could perform that task? The dissolution of rock materials, the deterioration of ground ice, or the evacuation of magma by volcanism are three possible mechanisms meriting consideration.

The solution hypothesis suffers from the need for soluble rocks and a suitable solvent. If Mars were rich in carbonatites and its volatiles were acidic, solution might occur. This seems a modest possibility at best.

Ground ice deterioration is attractive but suffers some qualifications. The ground ice would have to occur in segregated bodies, some means of causing its deterioration must be postulated, and 
the question of quantitative adequacy is all important. Woronow [1972], by using McElroy's [1972] analysis of Martian atmospheric evolution, gives reasons for thinking that the amount of water outgassed during the lifetime of Mars is wholly inadequate to produce the $2-$ to $3-\mathrm{km}$ subsidence suggested by chaotic terrain, even if all the water were concentrated as ground ice solely under the chaotic terrain areas. The more generous estimates of Sagan and Mullen [1972] also appear insufficient.

Another troubling problem is the depth of freezing required unless the ice were concentrated in a single layer just below the surface. If Martian frozen ground is postulated to have a generous $20 \%$ segregated ice content, freezing to a depth of $10 \mathrm{~km}$ would be required to yield 2 $\mathrm{km}$ of subsidence upon deterioration of the ground ice. This may not be an impossible depth, but it strains the limit of seemingly reasonable assumptions.

Even though the creation of large areas of chaotic terrain, inset $2-3 \mathrm{~km}$ below the upland, solely through ground ice deterioration may be questioned on quantitative grounds, ground ice may still have played a significant role in the recession of bounding escarpments, in the development of wall side slump blocks, and in the further breakup of the chaotic blocks created by collapse. There are also areas of chaotic terrain that do not look as though they had experienced much subsidence, perhaps just enough to initiate cracks that were then widened into chasms by ground ice deterioration (Figure 3). The thought that small scattered patches of chaotic terrain (Figure 6b) might be created by the local destruction of ground ice is also appealing.

Another argument has been advanced by McCauley et al. [1972] regarding the possible role of ground ice in chaotic terrain formation. In places, large, seemingly scoured channels emerge full-born from areas of chaotic terrain. These authors suggested that the channels were occupied by huge floods of water, resulting from melting of ground ice, which burst forth on the Martian surface like a Spokane-type flood [Bretz, 1969]. The vacated areas presumably collapsed into chaotic terrain.

If deterioration of ground ice is not the only or even the principal cause of chaotic terrain, the subsurface movement of magma in association with volcanism seems the other most likely agent. This thought is supported by the general prox- imity of the principal areas of chaotic terrain to the major recent volcanic fields in the northern hemisphere of Mars. It may be that volcanic subsidence owing to withdrawal of magma has initiated the development of chaotic terrain, which was then furthered by ground ice deterioration.

Acknowledgments. So many people have played a part in contributing to the success of the Mariner 9 photographic mission that to enumerate any by name does disservice to others unmentioned. Those people who have had a role in this great scientific adventure will know it and will, we hope, take satisfaction from publication of the results.

\section{References}

Bretz, J H., The Lake Missoula floods and the channeled scabland, $J$. Geol., 77, 505, 1969.

Carr, M. H., Volcanism on Mars, J. Geophys. Res., 78 , this issue, 1973.

Hartmann, W. K., Martian cratering, 4, Mariner 9 initial analysis, J. Geophys. Res., 78, this issue, 1973.

Kliore, A. J., G. Fjeldbo, B. L. Seidel, M. J. Sykes, and $P$. M. Woiceshyn, $S$ band radio occultation measurements of the atmosphere and topography of Mars with Mariner 9 extended mission coverage of polar and intermediate latitudes, $J$. Geophys. Res., 78 , this issue, 1973.

Leighton, R. B., and B. C. Murray, Behavior of carbon dioxide and other volatiles on Mars, Science, 163, 136, 1966.

McCauley, J. F., M. H. Carr, J. A. Cutts, W. K. Hartmann, Harold Masursky, D. J. Milton, R. P. Sharp, and D. E. Wilhelms, Preliminary Mariner 9 report on the geology of Mars, Icarus, 17, 289, 1972.

McElroy, M. B., Mars: An evolving atmosphere, Science, 175, 443, 1972.

Milton, D. J., Water and processes of degradation in the Martian landscape, J. Geophys. Res., 78, this issue, 1973.

Price, L. W., The periglacial environment, permafrost, and man, Resour. Pap. 14, 88 pp., Amer. Ass. Geogr., Washington, D. C., 1972.

Ryan, J. A., The case against thermal fracturing on the lunar surface, J. Geophys. Res., 67, 2549, 1962.

Sagan, C., and G. Mullen, Earth and Mars: Evolution of atmospheres and surface temperatures, Science, 177, 52, 1972.

Sharp, R. P., Mars: South polar pits and etched terrain, J. Geophys. Res., 78, this issue, 1973.

Sharp, R. P., L. A. Soderblom, B. C. Murray, and J. A. Cutts, The surface of Mars, 2, Uncratered terrains, J. Geophys. Res., 76, 331, 1971.

Woronow, A., Origin of the Martian chaotic terrains, Science, 178, 649, 1972.

(Received January 4, 1973; revised March 14, 1973.) 